\title{
Mitigation of Voltage Flicker at Smart Loads with Renewable (Wind) Energy in Distribution Systems
}

\author{
Santhosh G, Vani K, Srikanth B, Pravalika P
}

\begin{abstract}
This activity handles displaying and furthermore control of astute tons for request reaction organization under improved invasion of reasonable power ages (RPGs) at desperate degree. The raised penetration of RPGs, particularly twist control at particular degree, is defined with harming impact on voltage impact. An irreversible magnet synchronous machine based volatile rate wind control transformation structure is planned with a breeze rate considering stochastic and furthermore routine effects. The recreated wind control directly into the flow structure produces stochastic and additionally consistent power fluctuations. For the tons require criticism organization, fullconnected self-commutated catches based converters are utilize to control sharp tons (SLS). These SLs are over seen for partaking in structure transports voltage strategy and in addition glints decrease. From disperate calculations, it is observed that SLs work in improving the voltage measurements of the examination feeder.
\end{abstract}

Index Terms - Reasonable power ages (RPGs),control sharp tons(SLs), Synchronus machine, Wind Control, Feeder, Voltage impact, Power Fluctuations.

\section{INTRODUCTION}

The Canadian govt settled a goal to cut down $20 \%$ ozone exhausting substance weaken by 2020 thinking about standards of the year 2006 [1] most of the targets are anticipated to justify through viable influence ages (RPGs) in such chose, cash related and moreover positive course of action driven air.It causes the strategy for future structure certainly intentionally supervised in light of RPGs as oppose to customer parts to such a degree, to the point that power fragments is continuing and what's more eco system safe. Among the distinctive bothers that make by virtue of high infiltrations of RPGs, voltage administer, diminishing voltage fluctuations in perspective of glimmers, hang, swell and ordinariness control are mulled over as prime control destinations [2] To decide such burdens, fixes exist in theory works, for instance, raised score of a stay by DG structure and furthermore utilizing storage space systems for giving inadequacy live tons require.

Revised Manuscript Received on June 10, 2020.

* Correspondence Author

Santhosh G*, Assistant Professor, Electrical and Electronics Engineering, Siddhartha Institute of Technology \& Sciences, Hyderabad, India.

Vani K, Assistant Professor,Electrical and Electronics Engineering, Siddhartha Institute of Technology \& Sciences, Hyderabad, India.

Srikanth B, Assistant Professor, Electrical and Electronics Engineering, Siddhartha Institute of Technology \& Sciences, Hyderabad, India.

Pravalika P, Assistant Professor, Electrical and Electronics Engineering, Siddhartha Institute of Technology \& Sciences, Hyderabad, India.

(c) The Authors. Published by Blue Eyes Intelligence Engineering and Sciences Publication (BEIESP). This is an open access article under the CC BY-NC-ND license (http://creativecommons.org/licenses/by-nc-nd/4.0/)
Among these organizations, raised situating of a stay by device and furthermore high score of the storage space structures challenge the development of overseeing experts to help trusted in attack of RPGs with a particular ultimate objective to reduce nonrenewable fuel source permit and furthermore carbon impression to guarantee condition. Lift in the situating of stay by DG structure underpins resources and utilitarian expense of force system and moreover decreases the benefits of boosting essentially more systems of RPGs. Many sorts of storage space systems have truly been enabled and besides work with control structure in light of their transients, gadget term and what's more whole deal of storage space limit [3]-[5] Nevertheless, their immense execution, capital expenses and furthermore locale demands are constantly open to address. Besides, winning styles are to release RPGs close to the tons work places in order to cutting down line mismatches and moreover to less included support of transmission structures. Since wherever on, substantially more entrance of RPGs with spread structure is anticipated in years to coming. The need side association is one more opted answer for alleviating abnormality of the RPGs into the power system. All through high power age from RPGs, the tons require is upheld in future all through cut power age, the reduction of tons require happens. Parts required strategies are recognizes, for instance, those dealing with use of control storage space and apart straight on-off control of Non-fundamental tons (NCLs) [6]- -[7] Nevertheless the most of these structures appropriate for parts seeing in time structures of hrs and do not work randomly other than utilizing use of battery control storage space (BES) method.

\section{LITERATURE REVIEW}

Most of these destinations are anticipated to fulfil with eco-pleasing power ages (RPGs) in such chose, practical, cash related and what's more awesome game plan driven air. The proposed intrusion of RPGs uses disperate points of interest despite specific obstacles to the steadiness of philosophy of mass power system. These RPGs basically don't associate with customers tons require in time runs as a result of its high irregularity. In this manner, it accomplishes among the fundamental purposes behind improving the power system.

The non-boundless fuel source and moreover hydro based nuclear power plant play huge commitment in regulating voltage and also consistency of structure and besides along these lines in supporting the technique utilizing automated age control. The circumstance is utilitarian with accordingly less entrance of RPGs i.e. 10- - 15\%. Regardless as a result of raised entrances of such RPGs (50- - 60\%),

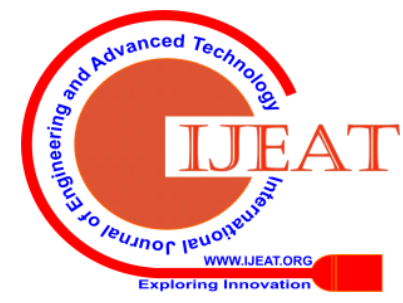


it will without a doubt be harder also for ordinary nuclear power plant to get included successfully in keeping security of the network.

Laying out and also control of insightful parts for ask for response seeing under raised attack of eco-obliging power ages (RPGS) at stream degree with the ultimate objective that Modelling and besides control for a whole structure voltage resource converter based ES have truly existed for grid transport voltage govern is suggested. The enhanced entrance of RPGS, especially bend control at scattering degree, is related with hurting sway on voltage high bore. A whole deal magnet concurrent generator Based volatile rate wind control change system is arranged with a breeze rate thinking about stochastic well as would be expected impacts. The imitated wind control specifically into the spread system makes stochastic and what's more standard power varieties. For the parts require input checking, fullassociate self-commutated gets based converters are utilized to supervise keen packages (SLS). These SLS are supervised for sharing in lattice transport voltage run and besides flashes diminish. To clear perfect breeze control, the time of power at volatile consistency is required. The PMSG rate is coordinated for accomplishing perfect power consider seeing under replace wind rate. It is obtained with controlled changing of Machine Side Converter (MSC) The MSC is associated in successive setup with Grid-Side Converter (GSC) with ordinary DC transport. The DC transport is made do with a capacitor to keep up voltage at its genuine for capable control of the two converters. The MSC gifts time of power at volatile consistency making use of control on PMSG rate.

\section{METHODOLOGY}

This segment presents brief review of the displaying and control utilized for the PMSG based VSWECS. A breeze turbine is associated in outfit less form with a multi post low speed three stage PMSG. The vacillations in yield intensity of VSWECS are seen because of wind speed varieties, wind shear and the pinnacle shadow impacts. The breeze speed varieties are viewed as stochastic in nature while the breeze shear and tower shadow impacts are viewed as occasional in nature. The intermittent impacts rely upon geometry of a turbine and named as 3p motions for a three-sharp edge wind turbine. Because of intermittent impacts, the yield intensity of wind vitality replacestructures drops three times for every transformation of a breeze turbine. For the displaying reason, these stochastic and occasional impacts are acquired utilizing proportionate breeze speed.

To separate greatest breeze vitality, the age of intensity at volatile recurrence is required. The PMSG speed is controlled for accomplishing greatest power point following under replace in wind speed. It is gotten through controlled exchanging of Machine Side Converter (MSC). The MSC is controlled utilizing field arranged calculation in synchronously turning stator transition outline for ideal torque control like work introduced . The MSC is associated in consecutive arrangement with Grid-Side Converter (GSC) with regular DC transport. The DC transport is upheld with a capacitor to settle voltage at its terminal for compelling control of the two converters. The MSC permits age of intensity at volatile recurrence utilizing control on PMSG speed.

\subsection{Control of GSC}

The GSC is likewise controlled in field-situated mode with its reference outline lined up with the structure voltage. The dynamic power conveyed from the MSC is quickly hanged to the lattice through the GSC. The dynamic power control is gotten through the GSC with direction of the DC transport voltage. Utilizing the voltage replacea transport 2 because of variance in control age at transport 3 is given as,

$$
\begin{aligned}
\Delta \mathrm{V}= & \mathrm{V}_{3}-\mathrm{V}_{2}=\left(\mathrm{R}_{\mathrm{w}}+\mathrm{j} \mathrm{X}_{\mathrm{w}}\right) \mathrm{I}_{32}=\left(\mathrm{R}_{\mathrm{w}}+\mathrm{j} \mathrm{X}_{\mathrm{w}}\right) \\
& \times \frac{\left(\Delta \mathrm{P}_{\mathrm{w}}-\mathrm{j} \Delta \mathrm{Q}_{\mathrm{w}}\right)}{\mathrm{V}_{3}} \\
\Delta \mathrm{V}= & \frac{\mathrm{R}_{\mathrm{w}} \Delta \mathrm{P}_{\mathrm{w}}+\mathrm{X}_{\mathrm{w}} \Delta \mathrm{Q}_{\mathrm{w}}}{\mathrm{V}_{\mathrm{q}}}+\mathrm{j} \frac{\mathrm{X}_{\mathrm{w}} \Delta \mathrm{P}_{\mathrm{w}}-\mathrm{R}_{\mathrm{w}} \Delta \mathrm{Q}_{\mathrm{w}}}{\mathrm{V}_{\mathrm{g}}}
\end{aligned}
$$

where $\Delta \mathrm{V}, \Delta \mathrm{Pw}$ and $\Delta \mathrm{Qw}$ are the change in voltage, active and reactive power injections at bus 3 .

For the scattering feeder, all things considered, the whimsical bit of the above Equation is overlooked as result of little sum with low $\mathrm{X} / \mathrm{R}$ extent [7]. Pondering the real bit of above Equation, the voltage changes can be diminished by imbuing reverse sign of responsive power $\mathrm{Qw}$ at transport 3. The unused furthest reaches of GSC is used to imbue responsive power at transport 3 as demonstrated by the bove Equation. Nevertheless, the structure couldn't work satisfactorily and gigantic voltage fluctuations in V3a, V3b and V3c at wind transport are seen, which are obvious from the gained results as showed up in Fig. 3. Effects of these voltage differences spread in exchange parts of test feeder. It is a direct result of the weak scattering feeder with low X/R extent (pondered 0.5 for this circumstance). Assortments in three-organize feeder current are in like manner seen from transport 3 to 2 on account of roken breeze control age.

In this examination, the ES based SLs are inquired about to diminish voltage changes and flickers at transport 2 due to broken breeze control age. Fig. shows the square outline of plan used for control of ES in each phase for ask for response organization and controlling the pile transport terminal voltages under invasions of RPGs in scattering feeder. The vehicle 2 voltage is distinguished and its root mean square regard is gotten which is isolated using a low pass Butterworth channel tuned at $60 \mathrm{~Hz}$ to allow low repeat assortments. The reference rms transport 2 voltage. 


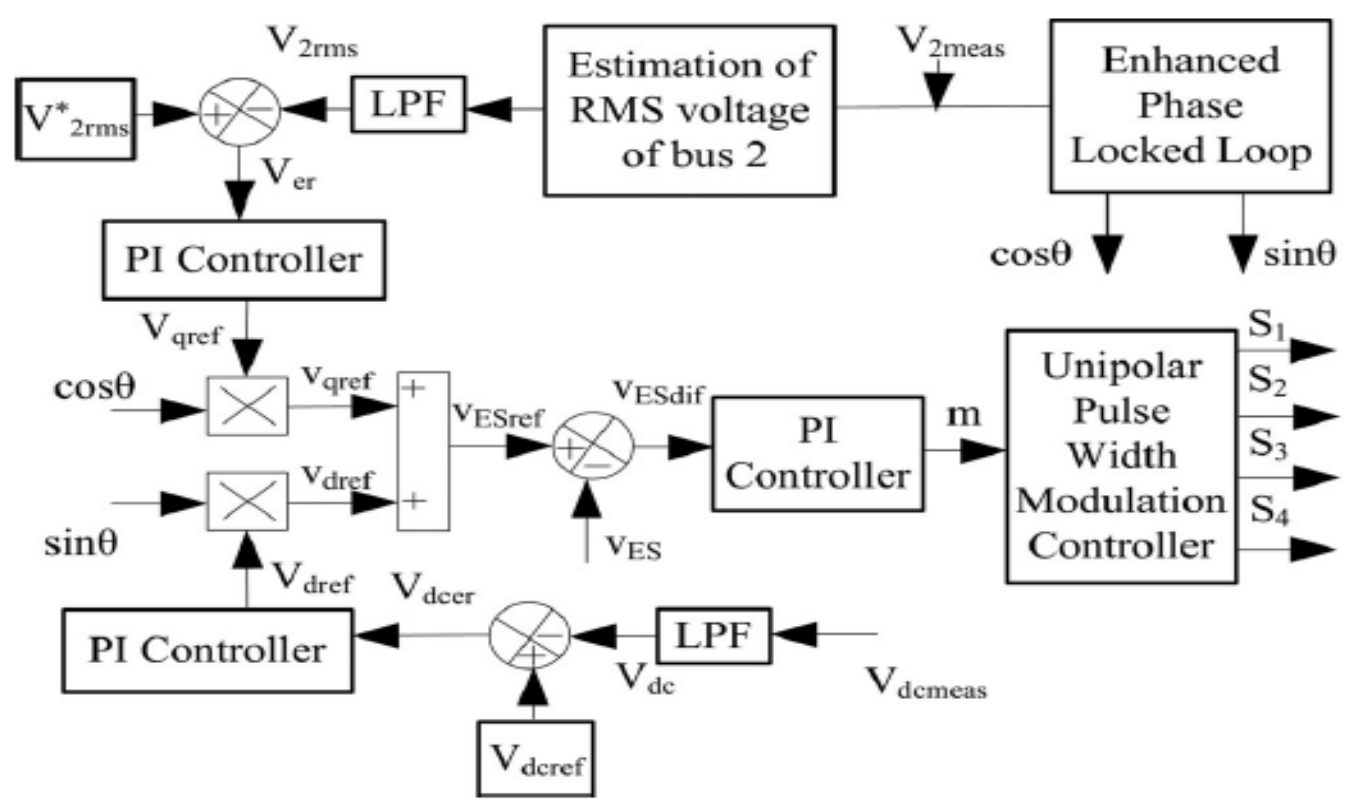

Fig.3.1. Control scheme for SLs.

\subsection{With Out ES:}

For this situation examine, the impact of infusion of discontinuous breeze control on the test feeder without the task of ES is exhibited. The mimicked wind speed displaying practical impacts is connected to twist turbine to consider effect of stochastic and deterministic varieties in twist speed on test feeder. The mean breeze speed is $9 \mathrm{~m} / \mathrm{s}$ while the base breeze speed is thought about $12 \mathrm{~m} / \mathrm{s}$. The reenactment results are gotten for $650 \mathrm{~s}$ with the goal that voltage flash seriousness files can be evaluated. Fig. indicates results as far as wind speed, rotational speed of wind turbine, PMSG wind created control, DC transport voltage and dynamic and responsive forces conveyed to matrix from GSC. It is seen that because of changeability in wind speed, created control contains discontinuity and is apparent in dynamic power conveyed by MSC (Pw) and GSC (Pgc) separately. Because of changeability of wind created control, expansive irritations in structure powers (Pg andQg ) are additionally recorded. Indeed, even the heap impedances (ZLs and ZLc) are viewed as consistent at stack transport and are seen in Fig. Unsettling influences in stack control (PLc and PLs) are additionally seen because of aggravations in transport voltages. Fig.3.1a demonstrates the power range thickness (PSD) of wind speed (vw) and wind created.

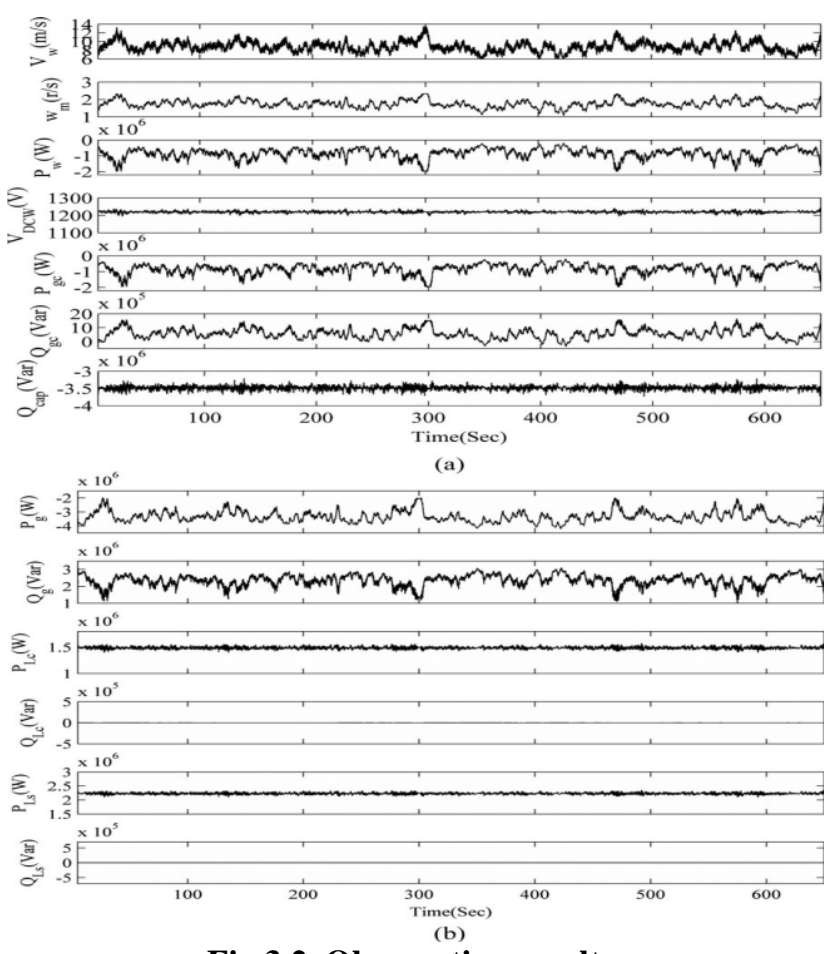

Fig.3.2. Observation results.

\subsection{With ES}

The action of ES is considered for its impact on execution lead of test feeder under change in wind control age. The ES is traded on by opening the CB of each stage. Fig. 3.1 exhibits the relentless state fleeting volatile plots of an ES for arrange 'a'. These results demonstrate organize voltage at stack transport (v2a ), stack current (i2as), dc transport voltage of an ES (vdc), ES channel capacitor voltage (vES), ES channel inductor current (iLES), NCLs voltage (vNC) and its present (iNC). From these results, it is seen that voltage v2a is phasor entire of voltages vES and vNC. The dc interface voltage vdc is controlled to its reference estimate $4 \mathrm{kV}$.

Published By:

Blue Eyes Intelligence Engineering

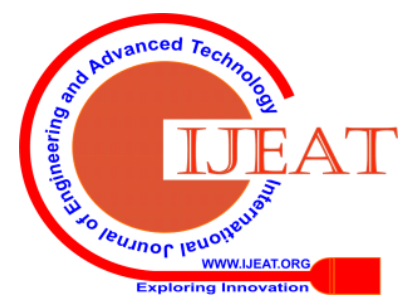


Regardless, swell repeat of capacitor voltage is twofold the supply repeat, which is a general wonder present at the DC transport of single-organize full expansion converter. Additionally, to show the assignment of an ES under replacein wind made control, Results obtained in regards to Pw, SLs dynamic power (PLs) at organize 'a', rms voltages at transport 2 for arrange 'a' (v2arms), and rms voltages of ES (vESrms). It is found that assortments in ES voltages are seen under replacein $\mathrm{Pw}$ to vary PLs. Fig. 10 shows dynamic and responsive power assortments at transport 1 and 2 with an ES under idea. From these results, disperateiates in PLs and QLs can be seen easily in connection with Case-I. It clearly demonstrates that under utilitarian undertaking with an ES, these SLs dynamic and open powers move under replacein wind control age so voltage profile upgrades at each vehicle. Fig. 3.2(a) demonstrates three-organize rms voltages and streams at transport 1 .

\section{SIMULATION RESULTS}

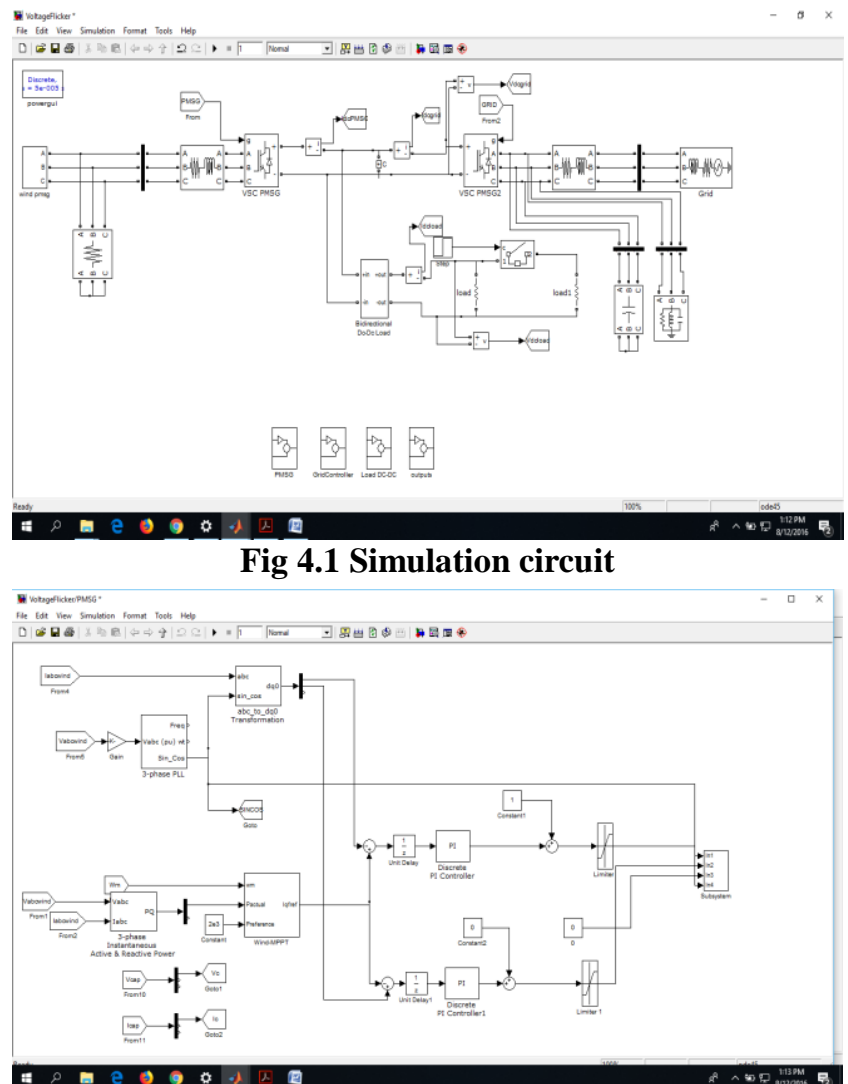

Fig 4.2 Proposed Controller circuit at Machine side converter

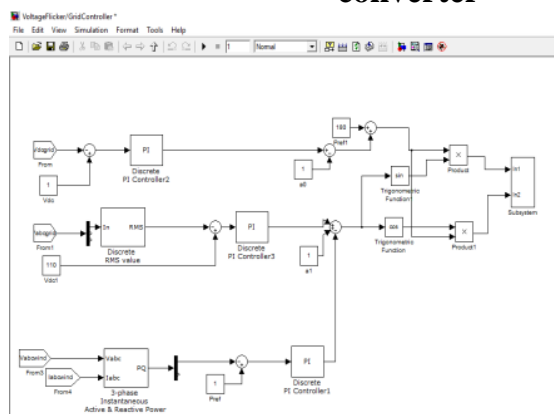

Fig 4.3 Proposed Controller circuit at Grid side converter

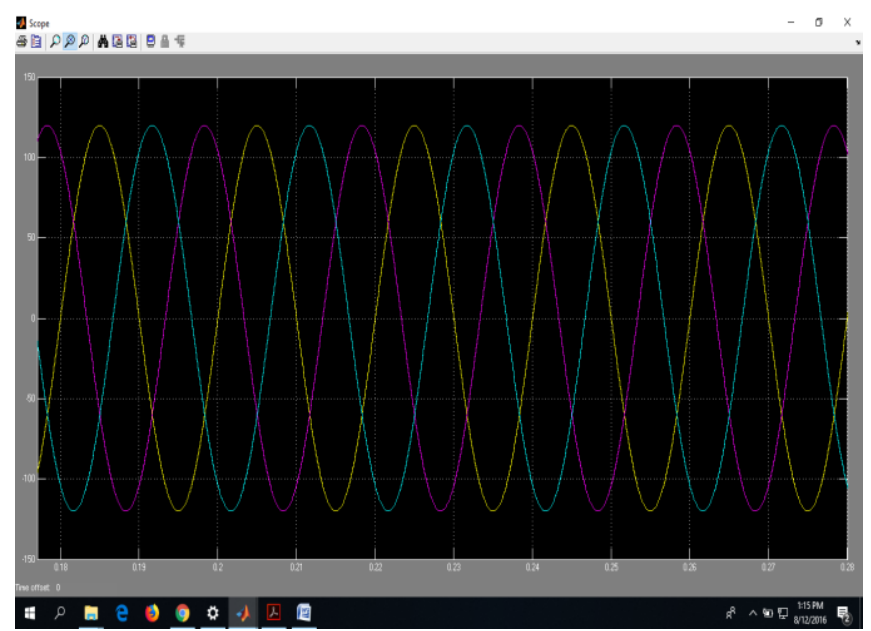

Fig 4.4 Voltage across the Source side

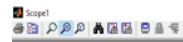

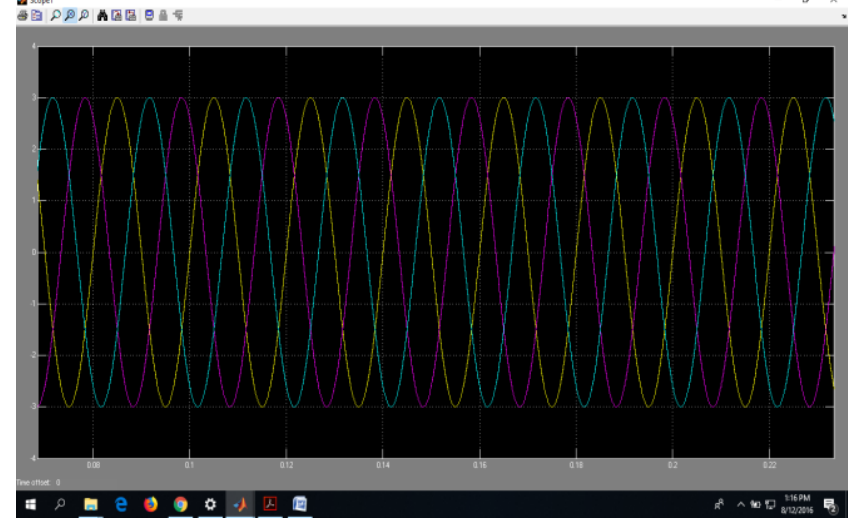

Fig 4.5 Currents across the generation side

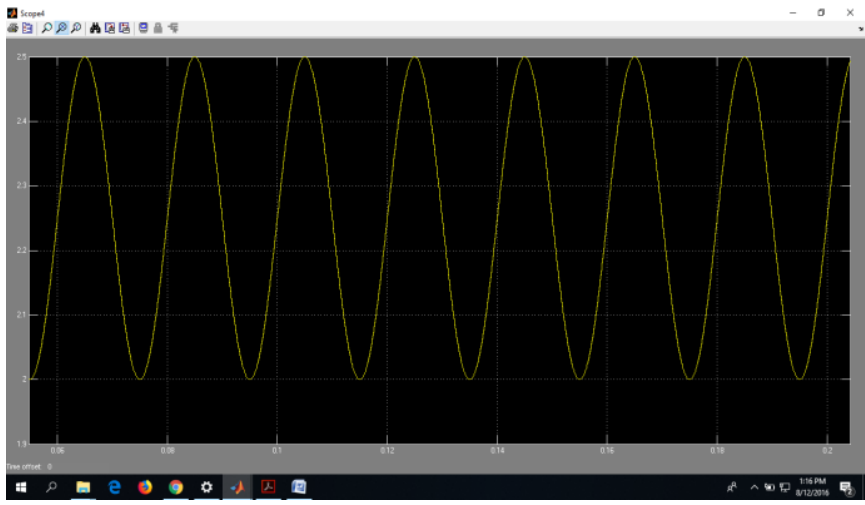

Fig 4.6 Voltage across the VSC2

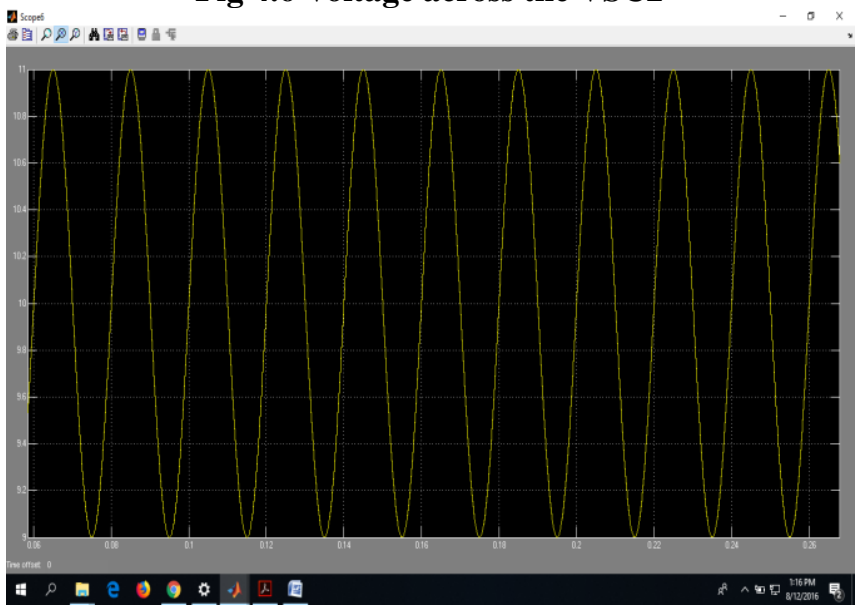

Fig 4.7 Current across the VSC2

Published By:

Blue Eyes Intelligence Engineering \& Sciences Publication 


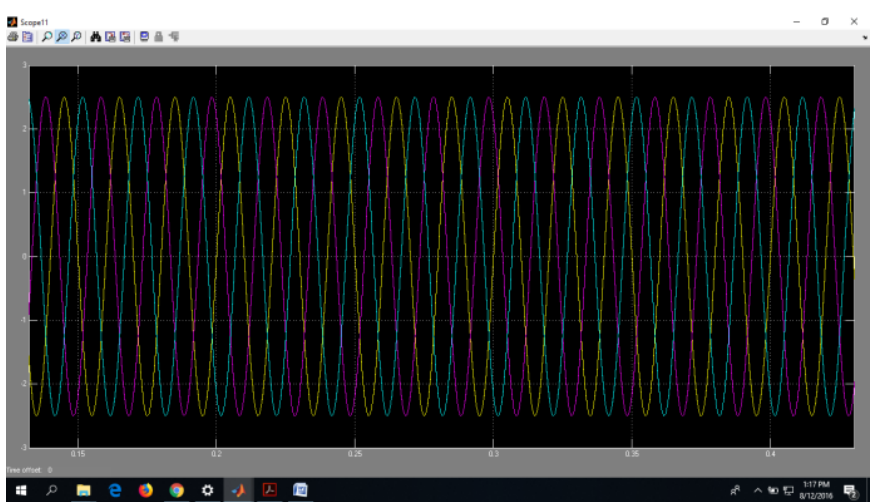

Fig 4.8.Grid voltage

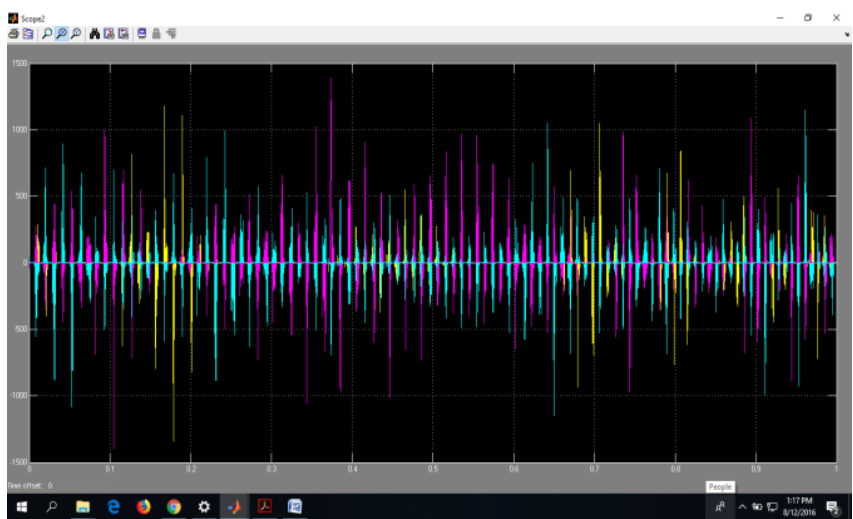

Fig 4.9 Voltage flicker

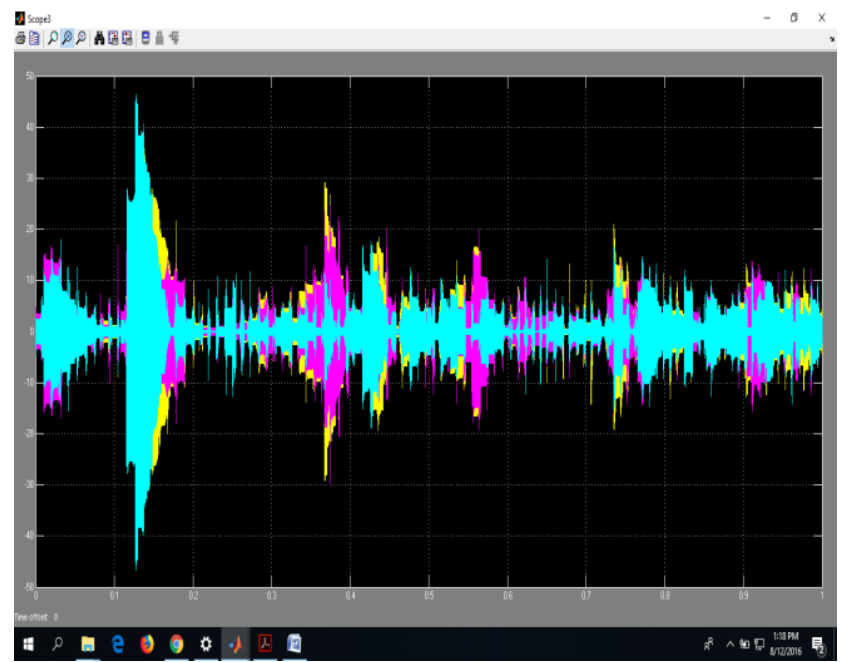

Fig 4.10 Current flickers

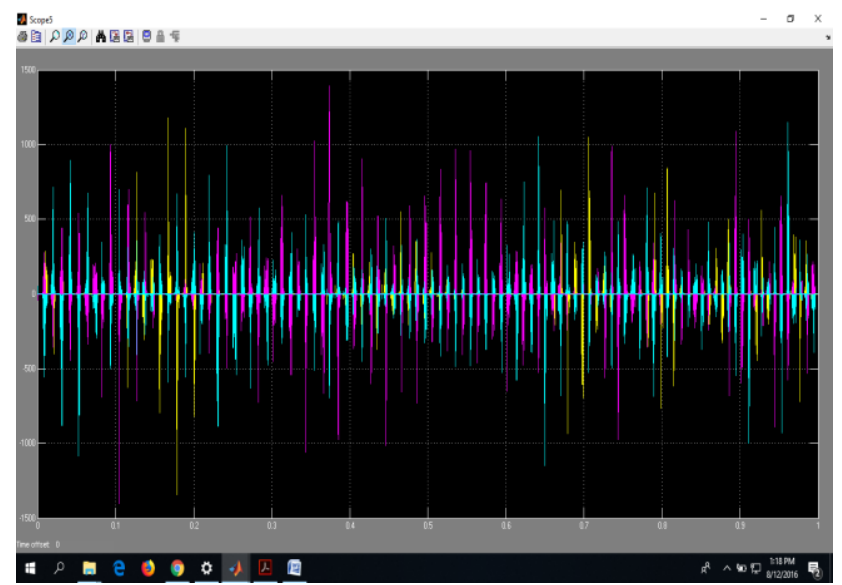

Fig 4.11 Power flickers

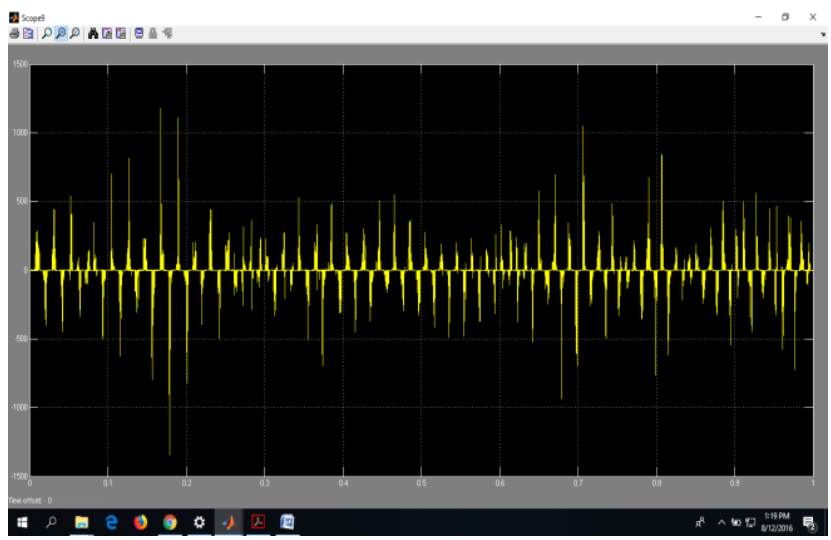

Fig 4.12 Capacitance flickers

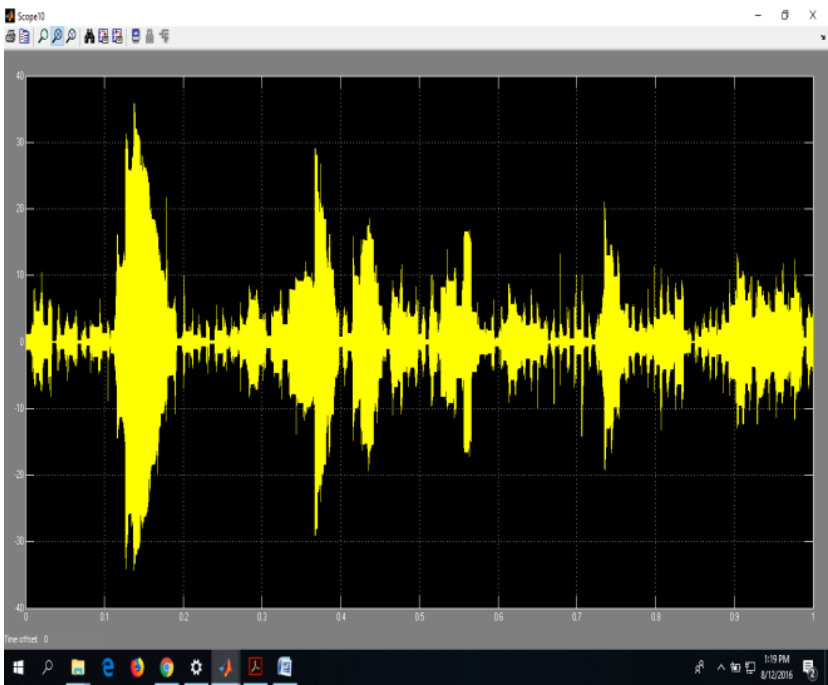

Fig 4.13 Current across the capacitor

\section{CONCLUSION}

The electric spring based clever burdens have been used for stack ask for response organization under MW measure PMSG in VSWECS under dispersal system. Showing and control for a full expansion voltage source converter based ES have been presented for organize transport voltage bearing. To duplicate commonsense breeze control age and its mixture in to the system, wind speed has been exhibited considering its stochastic and deterministic parts. The examination showed under Case-I have displayed that fluctuating breeze control implantation achieved voltage agitating impacts and outrageous voltage gleams expansion at each vehicle of flow sort out. In any case, the examination showed in Case-II indisputably exhibits that with adroit weights, voltage aggravations at all vehicles of spread feeder decreases and voltage gleam reality records are reduced. In this way, sending SLs using ES is exhibited an intense alternative among various courses of action in diminishing flashes in the test feeders.

\section{REFERENCES}

1. M. Yekini Suberu, M. Wazir Mustafa, and N. Bashir, "Essentialness amassing structures for feasible power source control zone coordination and help of intermittence," Renew. Oversee. Imperativeness Rev., vol. 35, pp. 499- 514, Jul. 2014.

2. S. Vazquez, S. M. Lukic, E. Galvan, L. G. Franquelo, and J. M. Carrasco, "Essentialness Storage Systems for Transport and Grid Applications," IEEE Trans. Ind.

\section{Published By:}

Blue Eyes Intelligence Engineering

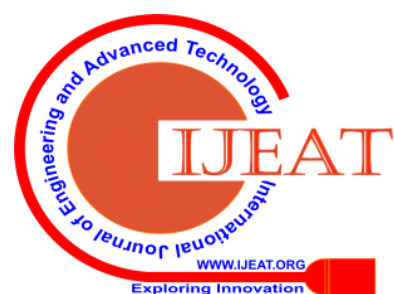


Electron., vol. 57, no. 12, pp. 3881- 3895, Dec. 2010.

3. M. G. Molina and P. E. Mercado, "Power Flow Stabilization and Control of Microgrid with Wind Generation by Superconducting Magnetic Energy Storage," IEEE Trans. Power Electron., vol. 26, no. 3, pp. 910- 922, Mar. 2011.

4. M.- E. Choi, S.- W. Kim, and S.- W. Website improvement, "Imperativeness Management Optimization in a Battery/Supercapacitor Hybrid Energy Storage System," IEEE Trans. Sharp Grid, vol. 3, no. 1, pp. 463- 472, Mar. 2012.

5. G. Qiu, C. R. Dennison, K. W. Knehr, E. C. Kumbur, and Y. Sun, "Porescale examination of effects of cathode morphology and electrolyte stream conditions on execution of vanadium redox stream batteries," J. Power Sources, vol. 219, pp. 223- 234, Dec. 2012.

6. X. Tan, Q. Li, and $\mathrm{H}$. Wang, "Advances and examples of imperativeness amassing development in Microgrid," Int. J. Electr. Power Energy Syst., vol. 44, no. 1, pp. 179-191, Jan. 2013.

7. N. R. Tummuru, M. K. Mishra, and S. Srinivas, "Dynamic Energy Management of Renewable Grid Integrated Hybrid Energy Storage System," IEEE Trans. Ind. Electron., vol. 62, no. 12, pp. 7728-7737, Dec. 2015.

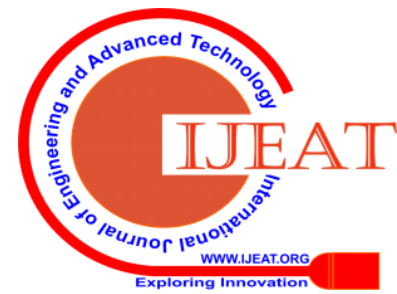

